\title{
O Estilo gráfico no jornalismo em quadrinhos $^{1}$
}

1. Versão revisada de trabalho apresentado nas 5as Jornadas Internacionais de Histórias em Quadrinhos, realizadas em agosto de 2018. Pesquisa realizada com apoio de bolsa de Mestrado concedida pela Coordenação de Aperfeiçoamento de Pessoal de Nível Superior - Brasil (CAPES).

\section{The graphic style in comics journalism}

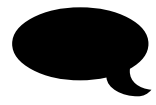

José Sampaio de Medeiros Neto ${ }^{2}$ Universidade Federal de Sergipe e Greice Schneider ${ }^{3}$ Universidade Federal de Sergipe

Resumo: Busca compreender as diferentes maneiras pelas quais o estilo gráfico pode se manifestar nas narrativas jornalísticas apresentadas em quadrinhos, e, mais precisamente, no modo como os traços autorais afetam o registro documental específico. Conceitos valorizados no campo jornalístico, como o imediatismo, a autenticidade e a objetividade são confrontados com o conceito de autoria gráfica. Para entender como se manifesta este contrato específico de leitura e para tratar destas naturais tensões que permeiam os quadrinhos, partimos do conceito de estilo visual, e mais especificamente o conceito de grafiação, encontrado na obra de Philippe Marion, que demostra como as marcas pictóricas do autor, sobretudo aquele inserido na narrativa, podem ativar campos de sensibilidade no receptor.

Palavras-chave: Jornalismo em Quadrinhos; Estilo; Grafiação.

Abstract: It examines the different ways in which graphic style is presented in journalistic graphic narratives, and more precisely in the way graphic authorship affects documentary limitations. Concepts valued in the journalistic field, such as novelty, authenticity and objectivity, are confronted with the concept of graphic authorship. In order to understand how this specific reading contract is manifested and to deal with these natural tensions that permeate comics, our point of departure is the concept of visual style, and more specifically the concept of graphiation, by Philippe Marion.

Keywords: Comics journalism, style, graphiation

Introdução

Os quadrinhos são marcados por uma relação gráfica fundamental, estabelecida pelo traço encontrado na linha desenhada (MARION, 1993, p. 15). Mas de que maneira esse traço gráfico de cada autor, que caracteriza seu estilo pictórico, pode afetar o dos quadrinhos? Esta influência ultrapassa os níveis textuais/informativos, relacionandose muito mais com o nível emocional que o desenho artístico pode acionar em relato jornalístico apresentado pelo sistema
2. Mestre em Comunicação pela Universidade Federal de Sergipe e graduado em Jornalismo pela Universidade Federal de Ouro Preto (UFOP). É chargista e autor de Curvas: reportagem em quadrinhos sobre o trânsito de Ouro Preto. Email: netomedeirosgr@gmail. com

3. Professora do Programa de Pós-Graduação em Comunicação da Universidade Federal de Sergipe. Doutora em Artes pela Katholieke Universiteit Leuven (Bélgica), Mestre em Comunicação e Cultura Contemporâneas pela Universidade Federal da Bahia, autora do livro What Happens When Nothing Happens: boredom and everyday life in contemporary comics (Leuven University Press). Email: greices@gmail.com. 
determinada audiência. Pode-se então visualizar um continuum, onde este traço gráfico autoral encontra-se, de um lado, mais próximo do chamado efeito de esboço', casos em que a autografia pictórica possa parecer menos ou mais fabricada pela mão humana, e, do lado oposto, mais próximo de traços mecânicos e regulares.

O modo como é modulada a linha de contorno (grossa ou fina, curva ou quebrada e assim por diante) é determinante para o efeito total do desenho e, por consequência, para o efeito total de uma história em quadrinhos, com também para a ilustração. Entender as diferenças entre os diversos modos de modular a linha nos põe em condições de entender algumas características fundamentais das imagens: por exemplo, sua dinamicidade, os efeitos infantis ou pictóricos, e assim por diante (BARBIERI, 2017, p. 29).

Neste artigo buscamos compreender como o estilo gráfico, tão característico ao sistema dos quadrinhos, se relaciona com as especificidades do fazer jornalístico. Ou seja, como os efeitos de grafiação (MARION, 1993) podem afetar o processo jornalístico, ampliando possibilidades narrativas $\mathrm{e}$ visuais. $\mathrm{O}$ texto é dedicado à discussão das diferentes maneiras pelas quais o estilo gráfico pode se manifestar nas narrativas jornalísticas apresentadas em quadrinhos, mais precisamente o modo como os traços autorais podem afetar o registro documental especifico no pacto de leitura jornalístico (em contraponto, por exemplo, com regimes supostamente mais realistas, como a fotografia) e de como esse discurso supostamente realista pode ser detectado. Dimensionamos, portanto, investigar quais as características e estratégias específicas do jornalismo feito em quadrinhos, em especial o modo próprio como ele administra informaçóes e agencia como essa especificidade pode ter consequências na experiência de leitura.

É perceptível, por exemplo, como representar notícias em um sistema tão complexo afeta o tempo de produção, já que a reportagem será construída através de textos e desenhos, e que estes, a depender da marca autoral, podem conter mais ou menos níveis de detalhamento. Por isso, a novidade (FRANCISCATO, 2005), uma das temporalidades mais caras no jornalismo, pode ser comprometida nos quadrinhos. Assim, "investigar a atividade em termos de sua mediação discursiva ajuda a desfazer mitos na discussão crucial sobre o papel do jornalismo na era do 'tempo real"' (MORETZSOHN, 2002, p. 117). Desta forma, é importante aqui distinguir aquelas produções do jornalismo em quadrinhos (JQ) que se aproximem de produçóes massivas, caracterizadas pelas hard news, daquelas em que o tempo de produção se amplia, como a reportagem em quadrinhos.

A tensão entre os princípios jornalísticos e o uso mais historicamente corrente de narrativas fantasiosas nos quadrinhos, também nos leva a uma inevitável discussão a respeito de gêneros, e uma tensão entre ficção e não-ficção. Buscaremos aqui perceber como outros cânones da prática jornalística são admitidos no jornalismo em quadrinhos. Assim, pretende-se analisar como este formato específico pode ser legitimado como produto jornalístico, caracterizado por alguns elementos, como a autenticidade e a objetividade, e investigar como os quadrinhos, um meio dominado por narrativas de ficção, dialoga com o “imperativo ético que estabelece a notícia como expressão da realidade" (GUERRA, 2008, p. 37-8). Ou seja, se é possível então atestar credibilidade jornalística a uma reportagem em quadrinhos, como é que se comporta o traço autoral, presente na linha gráfica do autor? E como esta se manifesta e se relaciona com o conteúdo informativo. 


\section{1 - O estilo gráfico nos quadrinhos}

Os quadrinhos são um complexo sistema ditado por imagens, que se apresentam de modo enunciável, descritível, interpretável e contemplável (GROENSTEEN, 2015). Interessa-nos compreender como a representação de mundos específicos pode ser construída através de desenhos (esboço ou regular) e tipologias (mais cursivas ou mecânicas). O intuito aqui é examinar de que forma esse gesto gráfico (MARION, 1993), constitui um elemento produtor de sentido, e em que níveis estes elementos aparecem.

Aqui é necessário, antes, diferenciar estilos de gêneros narrativos. Neste aspecto, deve-se esperar que a audiência perceba que "existem quadrinhos publicitários ou de propaganda, quadrinhos pedagógicos ou políticos e, ocasionalmente, quadrinhosreportagem onde predomina o objetivo de informar, de reportar" (GROENSTEEN, 2015, p. 29). Entendemos que o estilo gráfico, ou a identidade gráfica (MARION, 1993, p. 36), constitui um elemento produtor de sentido que remete ao perceptível do gesto, determinado em elementos caligráficos.

Palestina, obra que impulsionou Joe Sacco (2011) e popularizou o jornalismo em quadrinhos, destaca-se em meio às criações autobiográficas, caracterizada combinação entre personagens cartunizados e esquemáticos e cenários detalhados realísticos, oscilando entre uma tendência de aproximação e distanciamento. Este avatar autobiográfico cartunizado (WHITLOCK, 2006) transcende as dinâmicas produtivas das criações gráficas de não-ficção, uma vez que suas rotinas produtivas, ou seu compromisso ontológico, devem pertencer ao campo jornalístico, obedecendo assim a algumas destas dinâmicas, aliadas as especificidades do relato em quadrinhos. Neste sentido é possível tensionar as relações entre a liberdade artística da criação, sobretudo em seus níveis autográficos, e as dinâmicas pertencentes às criações legitimadas como conteúdo de caráter jornalístico.

E como esta grafiação pode ou não associar-se ao contrato de leitura jornalístico? No caso de Joe Sacco, além da similaridade visual com o estilo gráfico apontado anteriormente, o autor também se insere no contexto narrativo como um avatar autobiográfico (WHITLOCK, 2006). Por isso, em nosso entendimento, nos relatos atestados como jornalismo em quadrinhos, em que acontece este fenômeno, podemos então transcendê-lo, identificando o narrador como um avatar repórter, estabelecendo assim, o processo mimético da reportagem empreendida.

Uma das características do JQ, além do nível gestual gráfico, também é identificável por outros aspectos que podem ser confrontados, ou relativizados, com alguns pilares da deontologia jornalística. Diante de questões tão plurais, e dentro do amplo universo jornalístico, dentre alguns dos critérios pertinentes ao processo produtivo de gêneros textuais jornalísticos, que comporta especificidades produtivas em cada um, como o release, a reportagem, a crônica, a notícia, dentro do aspecto das hard news, o jornalismo literário e assim por diante, neste território, caracterizado pela presença do avatar repórter, abrese precedentes para questionamentos relativos ao atendimento de alguns dos importantes critérios para a prática, como a temporalidade, a autenticidade e a objetividade jornalística.

\section{2 - As temporalidades do jornalismo em quadrinhos}

No jornalismo em quadrinhos, o tempo de produção artesanal dos quadrinhos entra em conflito com demandas temporais especificas do jornalismo, como a instantaneidade, simultaneidade e a novidade. As restrições de duração provocam duas alternativas que afetam diretamente o estilo gráfico: de um lado, a manutenção da proximidade temporal com o evento prevê uma cobertura curta (através de tiras) ou um 
traço gráfico mais próximo do esboço, mais "rápido". Essa fragilidade do traço e ausência da arte final imprime também um caráter testemunhal de "desenhado ao vivo", atendendo à impressão de urgência do jornalismo factual.

A outra alternativa é adotar uma cobertura que permita uma maior distância temporal do acontecimento jornalístico, algo que acontece com um subgênero que relaciona elementos preocupados em contextualizar épocas sócio-temporais específicas. Assim,

Assuntos ou questões de interesse público ocorridos num intervalo mais ampliado de tempo, mas fora do conhecimento público (ou seja, mantidas em âmbito de 'segredo'), tornam-se atuais no momento em que o exercício jornalístico de investigação desfaz barreiras de 'segredo' e veicula esses conteúdos para informação e debate público. Este ato jornalístico pode ser denominado de revelação (FRANCISCATO, 2005, p.159).

A revelação pública parece ser portanto, o recorte temporal jornalístico mais adequado para contemplar as rotinas produtivas do jornalismo em quadrinhos, sobretudo em relação ao tempo gasto em produzir e assimilar o conteúdo proposto, aproximando-se assim de tendências jornalísticas menos tradicionais, como o novo jornalismo (; RESENDE, 2002) ou o jornalismo gonzo (PENA, 2007) por exemplo.

De acordo com a demanda temporal do veículo, portanto, pode-se produzir reportagens em quadrinhos mais ou menos complexas, com o traço mais ou menos definido, com mais ou menos pranchas, de acordo com a linha editorial destes veículos e a duração disposta de feitura das reportagens. Estas produções são caracterizadas por este tempo específico, que passa pelo processo de desenhar os textos e esquemas informativos, além de toda a apuração prévia comum as rotinas jornalísticas, algo que se aproxima das rotinas do movimento do slow journalism (LE MASURIER, 2015), que integra os vários movimentos de resistência à aceleração tecnológica do ritmo de vida contemporâneo.

\section{3 - Jornalismo em quadrinhos, estilo gráfico e autenticidade}

$\mathrm{O}$ estilo gráfico no jornalismo em quadrinhos também pode contribuir uma estratégia de atribuição de autenticidade, realçando o pacto de presença do suposto repórter-desenhista a partir da materialidade física do traço. O efeito de desenho "ao vivo" faz parte do discurso de reconstituição dos fatos a partir de uma observação atenta do jornalista narrador. Nesse sentido, o traço aqui funciona como um elemento de construção da identidade do jornalista, que se anuncia graficamente. Neste caso, a discussão pode se deslocar para estratégias discursivas do credenciamento do jornalista-quadrinista enquanto narrador confiável, digno de fé, e se afasta da discussão sobre possibilidades de manipulação da imagem - discussão suposta autenticidade da imagem fotográfica e seu valor atestatório e documental.

Essa condição de testemunho sugerida pelo traço pode também ser ainda reforçada pelo anúncio de um repórternarrador. Nesse caso, a grafiação passa a aliar a qualidade autoral à condição de testemunho: ou seja, a assinatura pictórica do sujeito emissor é capaz de denunciar (e não esconder) o narrador-desenhista.

No outro lado do espectro da grafiação, o traço mais mecanizado, com a adoção de estilos como, por exemplo, a linha clara, pode uniformizar o desenho e minimizar marcas de autoria. $\mathrm{O}$ próximo exemplo (figura 1) se afasta da impressão de rascunho, ou de seu estado mais 'cru', podendo ser interpretado como regularmente técnico, ou semelhante à mecanicidade do traço, onde é nítida a presença de uma arte-finalização digital. 


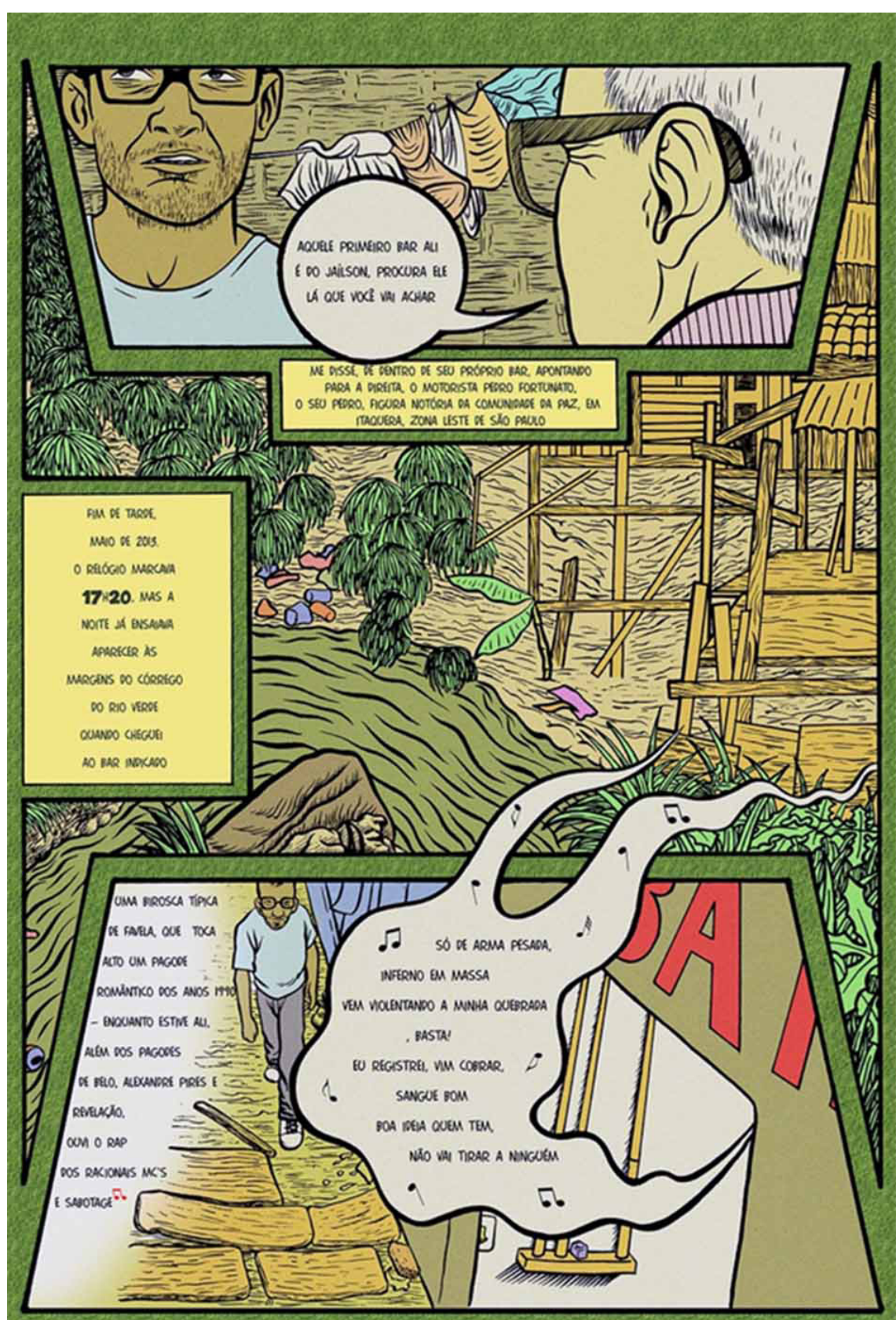

Figura 1 - Presença da arte-finalização digital no jornalismo em quadrinho.

Fonte: BARROS, Ciro; MAIA, Alvaro. A história de Jaílson, um operário da Copa. http://www.apublica. org/2014/07/a-historia-de-jailson-um-operario-da-copa/

4 - Jornalismo em quadrinhos, estilo gráfico e objetividade

A terceira dimensão fundamental na definição do jornalismo que pode ser tensionada com as especificidades dos quadrinhos é a objetividade, um de seus pilares, a propriedade que possibilita a factualidade, conferindo ao repórter credibilidade no reportar algo não presenciado pelo público. No caso da objetividade da imagem, os quadrinhos abrem espaço para se conceber uma forma de jornalismo visual que ultrapassa o discurso da objetividade meramente técnica tão presente no fotojornalismo (SOUSA, 2000).

Essa impressão de objetividade pode ser transmitida graficamente a partir de um discurso visual que valorize a representação 
fidedigna dos espaços e eventos, através de um alto nível de detalhamento, manutenção de proporções ou uso de convenções de representação realista do espaço, como a perspectiva, por exemplo. No requadro apresentado na figura 2, o sofrimento da senhora palestina procurando por joias da nora em meio aos escombros, enquanto as crianças brincam ao fundo, aliadas à peculiar grafiação de Sacco e seu poder monocromático reminiscente de convençóes do fotojornalismo moderno, acessam reações exclusivas a este tipo de emissão visual. $\mathrm{Na}$ composição de Sacco, além da perspectiva e detalhamentos cenográficos, é possível atribuir quais emoções sentia a senhora ao revirar os escombros, acionados principalmente pela contração de um olhar apreensivo:

Neste ponto, nos damos conta de que a representação dos gestos, longe de apenas nos restituir ao significado mais fortemente normatizado nos ritos, também serve à produção de um efeito de experiência vicária de testemunho, de simpatia sensorial, igualmente através da figuração das ações humanas (PICADO, 2005, p.24).

A perspectiva atua para além da estratégia de composição artística, também como informação visual, contrastando com o primeiro plano mais claro, e destacando os escombros de um prédio alvejado por mísseis e tiros de armas de grosso calibre. É curioso, portanto, notar que Sacco a considera sua pior criação. São justamente as escolhas que justificam a impressão visual de uma objetividade gráfica, que comprometem, segundo ele, seu grau emocional:

Considero "Hebron: por dentro da cidade", (...) minha pior matéria no jornalismo em quadrinhos. Não posso culpar o editor sênior, Joshua Cooper Ramo, que apostou no jornalismo em quadrinhos $\mathrm{e}$ me apoiou em cada passo. Acho que travei ao trabalhar para um veículo de passado tão ilustre, aí dispensei minha típica abordagem em primeira pessoa e voltei ao jornalismo bê-á-bá, objetivo, que aprendi na faculdade. Por esse motivo, fracassei em representar de forma adequada a grande injustiça que ocorre quando a movimentação livre de dezenas de milhares de palestinos está sujeita aos ditames de poucas centenas de militantes judeus dos assentamentos (SACCO, 2015, p. 32).

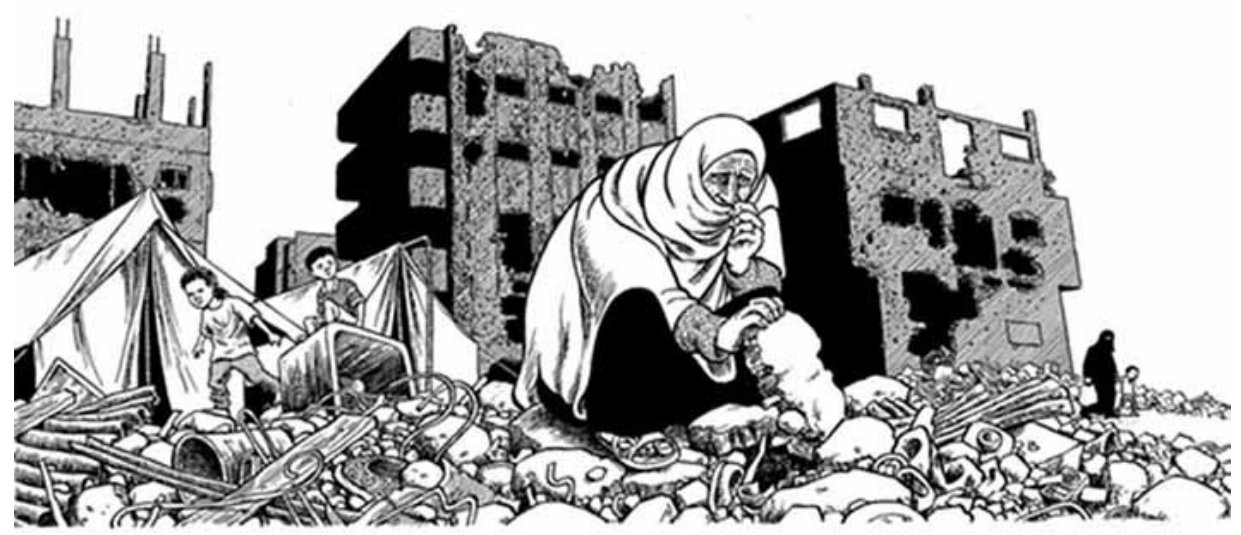

Figura 2 - Fragmento de Territórios Palestinos - Hebron: por dentro da cidade. Fonte: SACCO, Joe. Reportagens. São Paulo: Quadrinhos na Cia, 2016, p. 20-1. 
A produção do jornalismo em quadrinhos também pode enfatizar o imperativo denunciante e revelador do gênero ao reunir pesquisas e reproduções, textuais, e pictóricas, sobre algumas passagens deste tempo histórico. A impressão de cópia fidedigna de desenhos de documentos comprobatórios, como fotografias históricas, contribui para conferir um grau de objetividade às reportagens. É o caso, por exemplo, do trabalho de Robson Vilalba, em Notas de um Tempo Silenciado (2015), a respeito da memória da ditadura militar no Brasil e o Golpe de 1964. Vilalba reproduz graficamente algumas impressões da Marcha da Famía com Deus pela Liberdade, passeata que reuniu cerca de 500 mil pessoas e sedimentou de certa forma a intervenção militar (figuras 3 e 4). Nota-se como o artista reproduz ícones e estereótipos sedimentados naquele período através de imagens consolidadas da fotografia histórica, a partir de evidente pesquisa visual. A recorrência da mesma composição visual presente nas fotografias e repetição de elementos visuais e personagens constantes no imaginário coletivo da época, aliada ao traço detalhado do autor, sugerem ao leitor um senso de realismo ou proximidade visual. Esse realismo gráfico é reforçado pela presença de outros materiais atestatórios próprios do jornalismo (entrevistas com fontes, dados estatísticos, infográficos). É possível também perceber como a linguagem síntese de símbolos, ícones e estereótipos podem se relacionar com a verossimilhança e precisão relacional, uma vez que na própria comparação acima se percebe a reprodução de quatro placas presentes entre os manifestantes da passeata e que foram registradas pela fotografia e reproduzidas no primeiro requadro da prancha de Vilalba.

TI DE MARCO DE TIGH. SÄO PANLO.

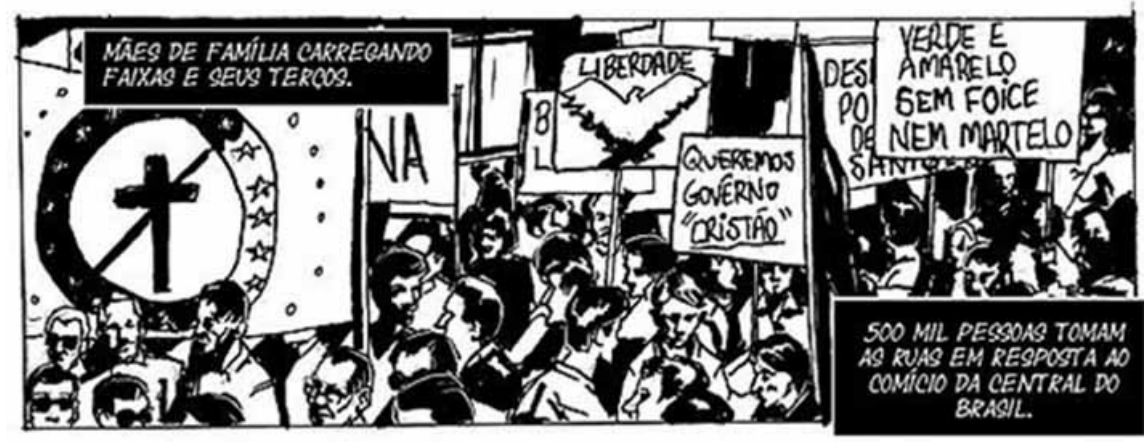

Figura 3 - Quadrinhos sobre passeata que antecedeu o Golpe de 1964 no Brasil.

Fonte: VILALBA, Robson. Notas de um tempo silenciado. Porto Alegre: Besouro box, 2015. Acervo dos autores.

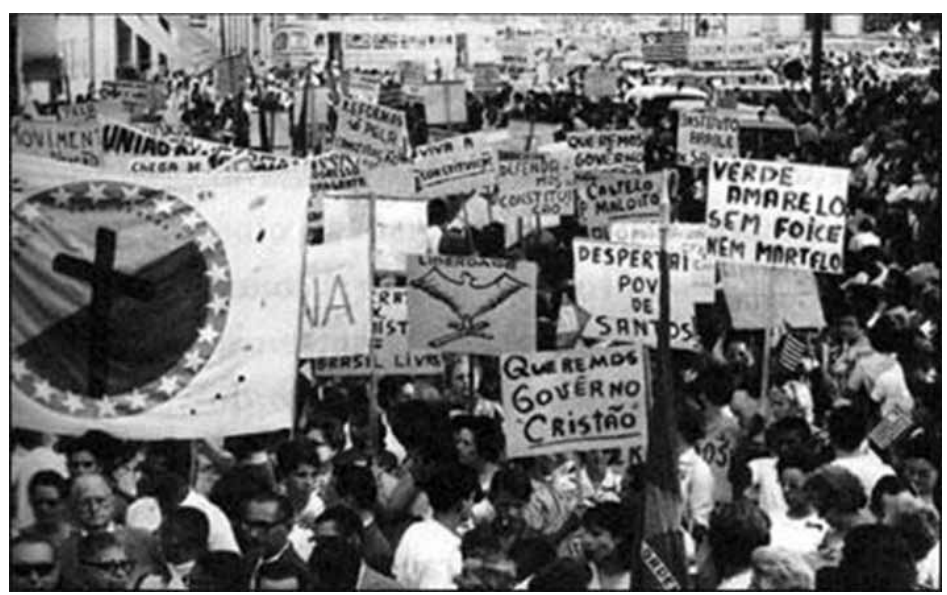

Figura 4 - Fotografia da Marcha da Família com Deus Pela Liberdade, 1964.

Fonte: Historiativa.Net 
A combinação, hoje contestada, entre aparência de representação mecanicamente produzida (como a fotografia) e valores como objetividade e autenticidade é o que, por muito tempo, elevou a fotografia à posição de imagem jornalística por excelência. No entanto, outros recursos podem ser explorados em diversas formas de representação visual que explorem, por exemplo, efeitos emocionais no espectador, ou até mesmo possibilidades de cruzamento de declarações de fontes. Allende, le dernier combat funciona como um contraponto nesse sentido. Assinada pela dupla Olivier Bras e Jorge González, a reportagem em quadrinhos narra as últimas horas de Salvador Allende no 11 de Setembro de 1973, no Chile. González faz uso de uma pesquisa histórica detalhada e combina composições visuais de imagens históricas a narrações de vários personagens e relatos ficcionais, alternando vozes narrativas. Aqui, a identidade gráfica é composta por uma grande mistura de estilos em um mesmo quadro, variando materiais, como carvão, pastéis (figura 5). Por um lado, as semelhanças com a imagem original (figura 6), o uso de perspectiva artificialis, a manutenção de proporções dos volumes e congelamento do instante aludem a certo teor fotográfico da imagem. Por outro lado, não há esforço de tornar invisíveis os artifícios humanos, e esconder o traço e presunção de ilusão e testemunho - é justamente o elemento artesanal que realça a subjetividade do momento e destaca seu lado emocional, a que o repórter não teria acesso de outra maneira.

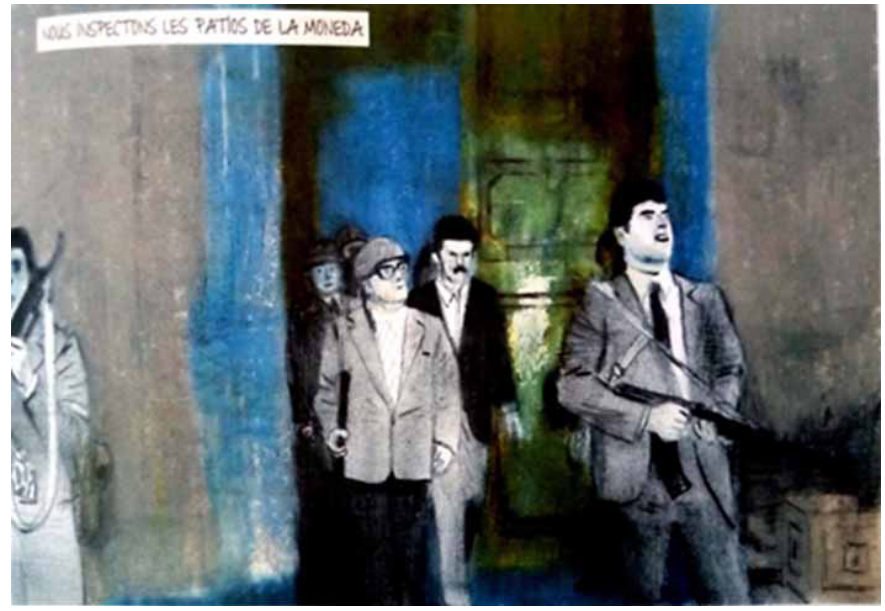

Figura 5 - Versão em quadrinhos da inspeção do pátio de La Moneda. Fonte: BRAS, Olivier, GONZÁLEZ, Jorge. Allende, le dernier combat, 2013. Acervo dos autores.

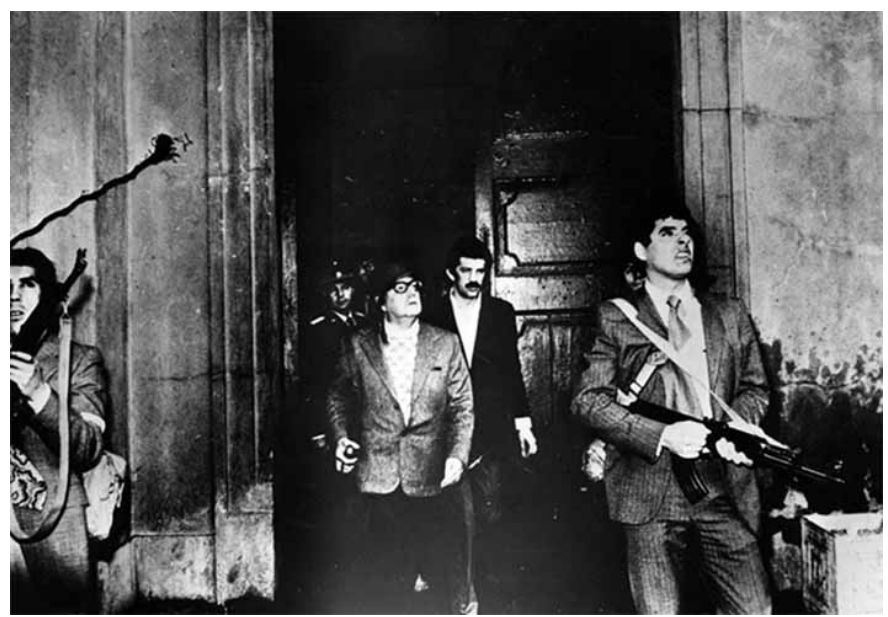

Figura 6 - Em sua última foto, Allende inspeciona o pátio do palácio presidencial. Fonte: LAGOS, Orlando, The New York Times, 1974. World Press Photo (site) <https://www.worldpressphoto.org/ collection/photo/1974/world-press-photo-year/orlando-lagos> 


\section{Considerações Finais}

Neste percurso tentamos estabelecer como o estilo gráfico, a partir do conceito de grafiação, negocia com valores próprios do campo jornalístico - a saber: novidade, autenticidade e objetividade, que muitas vezes são considerados como desafios ao jornalismo em quadrinhos, pela subjetividade do traço, ausência de mecanicidade do desenho, e longo tempo de feitura das reportagens. Muitos autores buscam replicar esses valores ao incorporar convençôes de outras formas como instrumento de legitimação do jornalismo em quadrinhos: aqui, o traço gráfico, objeto desse artigo, é costumeiramente tornado discreto, invisível, acessório. $\mathrm{O}$ objetivo aqui, no entanto, é também revelar casos nos quais esse traço gráfico assume um protagonismo e se mostra mais aparente, opaco, menos invisível.

Em um primeiro momento, vimos como a limitação temporal própria de produção artesanal de quadrinhos, aliada às rotinas produtivas e demandas temporais do jornalismo, podem acabar favorecendo gêneros específicos mais longos e demorados, como as reportagens e pautas de revelação pública. Do outro lado do espectro, no entanto, o traço rápido, próprio do desenho feito ao vivo, no calor do acontecimento, pode muitas vezes favorecer marcas de testemunho do desenhista e reforçar um senso de autenticidade raro, como os antigos sketches feitos à mão nos tribunais.

Em um segundo momento, analisamos certa tradição do jornalismo em quadrinhos tradicional em apostar em um traço supostamente mais fidedigno, que aparenta mecanicidade e precisão dos contornos $\mathrm{da}$ linha clara ou nível de detalhamento mecânico da fotografia, sugerindo a aparência e textura de imagens costumeiramente associadas a documentos. No entanto, o traço autoral, assim como nas assinaturas, também pode sugerir um efeito de valor atestatório. Aqui, a garantia de presença do desenhista e sua autoria através do estilo podem ser usados veículos poderosos de identificação. Mesmo o letreiramento manual, em detrimento do letreiramento homogêneo, concede um valor de autenticidade emocional do relato em primeira pessoa (ASSIS, 2018).

E, finalmente, em um terceiro momento, observamos a clássica questão da objetividade a partir de um (equivocado) confronto clássico do jornalismo visual, entre o desenho e a fotografia. Aqui, observamos os vários casos nos quais o próprio jornalismo em quadrinhos é informado não só pelo desenho testemunhal feito ao vivo, mas também pelo desenho de fotografias e outros documentos, enquanto fonte secundária. Como contraponto, trouxemos exemplos de casos em que é justamente a fuga rumo à subjetividade que permite a adesão a uma multiplicidade de pontos de vista e um processo de imersão emocional com o espectador que é reforçado justamente a partir da gestualidade do traço e das marcas materiais impressas na página.

\section{Referências}

ASSIS, Erico. Aproximaçôes entre letreiramento e tradução linguística na tradução de histórias em quadrinhos. (tese de doutorado) Programa de Pós-Graduação em Estudos da Tradução. Universidade Federal de Santa Catarina. Florianópolis, 2018.

BARBIERI, Danielle. As linguagens dos quadrinhos. São Paulo: Peirópolis, 2017. BARROS, Ciro; MAIA, Alvaro. A bistória de Jailson, um operário da Copa. Agência Pública, Julho de 2014. Disponível em: http://www.apublica.org/2014/07/ahistoria-de-jailson-um-operario-da-copa/ Acesso em 16 set. 2017.

BLAS, Olivier; GONZÁLEZ, Jorge. Allende, le dernier combat. La Revue Dessinée, Paris, v. 1, 2013

FRANCISCATO, Carlos Eduardo. A fabricação do presente: como o jornalismo reformulou a experiência do tempo nas sociedades ocidentais. São Cristóvão: Editora UFS; Aracaju: Fundação Oviêdo Teixeira, 2005.

GUERRA, Josenildo Luiz. O percurso interpretativo na produção da notícia. São Cristóvão: Editora UFS; Aracaju: 
Fundação Oviêdo Teixeira, 2008.

GROENSTEEN, Thierry. O sistema dos quadrinhos, Rio de Janeiro: Marsupial, 2015. LE MASURIER, Megan. What is slow journalism? Journalism practice, v. 9, n. 2, p. 138-152, 2015.

MARION, Philippe. Traces en cases: travail graphique, figuration narrative et participation du lecteur, Louvain-la-Neuve: Academia, 1993.

MORETZSOHN, Sylvia. Jornalismo em" tempo real": o fetiche da velocidade. Rio de Janeiro: Editora Revan, 2002.

PENA, Felipe. O jornalismo literário como gênero e conceito. Revista Contracampo, v. 2, n. 17, p. 43-58, 2007.

PICADO, Benjamim. Olhar testemunhal e representação da ação na fotografia. Revista da Associação Nacional dos Programas de PósGraduação em Comunicação-e-Compos, v.3, p.1-29, ago. 2005.

RESENDE, Fernando. Textuações: ficção e fato no novo jornalismo de Tom Wolfe. São Paulo: Fapesp, 2002.

SACCO, Joe. Área de segurança Gorazde: a guerra na Bósnia Oriental 1992-1995. São Paulo: Conrad, 2005.

Palestina. Edição: 1a. São Paulo:

Conrad, 2011.

- Reportagens. São Paulo:

Quadrinhos na Cia, 2016.

SOUSA, Jorge Pedro. Uma bistória crítica do fotojornalismo ocidental. Chapecó: Grifos, 2000.

VILLALBA, Robson. Notas de um tempo silenciado. Porto Alegre: Besouro box, 2015 WHITLOCK, Gillian. Autographics: The seeing" I" of the comics. MFS: Modern Fiction Studies, v. 52, n. 4, p. 965-979, 2006 